PROFESSOR CARL M PHILPOTT (Orcid ID : 0000-0002-1125-3236)

Article type : Original Manuscript

\title{
Current Use of Baseline Medical Treatment in Chronic Rhinosinusitis: Data from the National Chronic Rhinosinusitis Epidemiology Study (CRES)
}

\author{
Chief Investigator: Mr Carl Philpott, Senior Lecturer at University of East Anglia \\ and Honorary Consultant ENT Surgeon, James Paget University Hospital
}

Mr Carl Philpott ${ }^{1^{*}}$, Miss Sally Erskine ${ }^{1}$, Mr Rupert Smith*, Miss Claire Hopkins², Mr Naveed Kara

Mr Amir Farboud ${ }^{4}$, Mr Mahmoud Salam ${ }^{5}$, Mr Alasdair Robertson ${ }^{6}$, Mr Rob Almeyda , Prof B. Nirmal

Kumar $^{8}$, Mr Shahram Anari ${ }^{9}$, Prof Jaydip Ray ${ }^{10}$, Mr Russell Cathcart ${ }^{11}$, Mr Sean Carrie ${ }^{12}$, Mr Shahzada

Ahmed $^{13}$, Prof Hisham Khalil ${ }^{14}$, Dr Allan Clark*, Prof Mike Thomas ${ }^{15}$

${ }^{1}$ James Paget University Hospital NHS Foundation Trust, Gorleston, UK

*Norwich Medical School, University of East Anglia, Norfolk NR4 7TJ, United Kingdom

${ }^{2}$ Guys \& St Thomas Hospital NHS Foundation Trust

${ }^{3}$ County Durham \& Darlington NHS Foundation Trust

${ }^{4}$ Wrexham Maelor Hospital, Wrexham, Wales, UK

${ }^{5}$ Ipswich Hospital NHS Foundation Trust

${ }^{6}$ Queen Elizabeth University Hospital Campus, Glasgow, UK

${ }^{7}$ Royal Berkshire NHS Foundation Trust, Reading, UK

${ }^{8}$ Wrightington Wigan and Leigh NHS Foundation Trust, Wigan, UK

${ }^{9}$ Heart of England NHS Trust, Birmingham, UK

${ }^{10}$ Sheffield Teaching Hospitals NHSFT, Sheffield, UK

${ }^{11}$ Cumberland Infirmary, Carlisle, Cumbria, UK

${ }^{12}$ Freeman Hospital, Newcastle, UK

${ }^{13}$ University Hospitals Birmingham NHS Foundation Trust

${ }^{14}$ Derriford Hospital, Plymouth, Devon, UK

${ }^{15}$ Primary Care and population Sciences, University of Southampton, UK On behalf of the CRES group:

Chief Investigator: Mr Carl Philpott, Senior Lecturer at University of East Anglia and Honorary Consultant ENT Surgeon, James Paget University Hospital.

Miss Sally Erskine1, Mr Carl Philpott1^§, Dr Allan Clark, Miss Claire Hopkins2, Mr Alasdair Robertson4, Mr Shahzada Ahmed6, Mr Naveed Kara12, Mr Sean Carrie11, Mr Vishnu Sunkaraneni20, Prof Jaydip Ray17, Mr Shahram Anari7, Mr Paul Jervis10, Miss Jaan Panesaar18, Mr Amir Farboud5, Prof Nirmal Kumar3, Mr Russell Cathcart8, Mr Robert Almeyda14, Prof Hisham Khalil9, Mr Peter Prinsley13, Mr Nicolas Mansell15, Mr Mahmoud Salam16, Mr Jonathan Hobson19, Ms Jane Woods1, Dr Emma Coombes*.

This article has been accepted for publication and undergone full peer review but has not been through the copyediting, typesetting, pagination and proofreading process, which may lead to differences between this version and the Version of Record. Please cite this article as doi: 10.1111/coa.13012

This article is protected by copyright. All rights reserved. 
1James Paget University Hospital NHS Foundation Trust, Gorleston, 2Guys \& St Thomas' Hospital, London, 3Wrightington, Wigan \& Leigh NHS Foundation Trust, 4Southern General Hospital, Glasgow, 5Wrexham Maelor Hospital, Wales, 6University Hospitals Birmingham, 7Heart of England NHS Foundation Trust, Birmingham, 8Cumberland Infirmary, Carlisle, 9Derriford Hospital, Plymouth, 10Northampton General Hospital, 11Freeman Hospital, Newcastle, 12Sunderland Royal Infirmary, 13Norfolk \& Norwich University Hospital, 14Oxford University Hospitals, 15Royal Berkshire NHS Foundation Trust, Reading, 16The Ipswich Hospital, 17Sheffield Teaching Hospitals, 18Luton \& Dunstable Hospital, 19Warrington and Halton Hospitals NHS Foundation Trust, 20Royal Surrey County Hospital, Guildford, *Norwich Medical School, University of East Anglia, Norfolk NR4 7TJ, United Kingdom, §Spire Norwich Hospital.

NIHR portfolio ID: 12926; Funding: The Anthony Long Trust, the Bernice Bibby Trust.

This study is reported according to the STROBE statement for observational studies.

Key words: sinusitis; Administration, Intranasal; Patient Compliance; Therapeutic Irrigation;

otolaryngology

\section{Abstract}

\section{Objectives}

According to clinical and comissioning guidelines for chronic rhinosinusitis (CRS), patients being referred to secondary care should have failed primary medical treatment with nasal douching (ND) and intranasal corticosteroids (INCS). The study objectives were to identify the rate of specific medical therapy in CRS patients and establish any differences in medication use, for both CRS and associated medical conditions, between CRS phenotypes.

\section{Design and setting}

Case-control study in a secondary care setting.

\section{Methods}

Participant-reported study-specific questionnaire capturing free text data on current medication use at the time of study entry. Qualitative interviews with 21 participants also explored their experience of CRS and its management.

\section{Particpants}

Patients with both without (CRSsNPs) and with polyps (CRSwNPs).

\section{Main outcome measures}

Reported use of CRS-related and non-related medications.

\section{Results}

Within a total of 1243 CRS participants, current INCS usage was low (18\% in CRSWNPs, $12 \%$ in CRSsNPs); ND was being performed by only $1 \%$ of all participants. Bronchodilators and inhaled corticosteroids use was significantly higher in CRSwNPs participants $(p<0.0001)$. Antidepressants use was significantly higher in CRSsNPs (14\% versus $7 \%, p<0.0002)$. There

This article is protected by copyright. All rights reserved. 
were no significant regional variations in rates of INCS use, nor any significant influence of social deprivation.

\section{Conclusions}

The current use of baseline medical therapy in CRS appears to be very low, representing a combination of poor patient compliance, possible ineffectiveness of treatment and a lack of familiarity with current guidelines amongst general practitioners and some ENT specialists. Work is needed to disseminate guidelines to all practitioners involved and reduce unnecessary burden on existing healthcare resources for this common condition by ensuring timely referral and definitive management.

\section{Background}

Chronic rhinosinusitis (CRS) is a common inflammatory disorder of the respiratory tract defined by the presence of either nasal blockage and/or nasal discharge as well as loss of smell and/or facial pain/pressure for 12 weeks or more; this must be corroborated with endoscopic findings (mucopus/polyps) and/or radiological findings (CT scan opacification in sinuses) ${ }^{1}$. CRS affects a significant proportion of the adult population with a recent European study suggesting a prevalence of $11 \%$ in the UK ${ }^{2}$. Longitudinal data from the Clinical Practice Research Datalink (CPRD) shows that $1 \%$ these affected adults receive treatment from their GP each year with an average of $4 \mathrm{GP}$ visits ${ }^{3}$, and additionally this includes prescription of multiple medications with $91 \%$ receiving an antibiotic prescription ${ }^{4}$. There are no NICE guidelines and although international guidelines exist, ${ }^{1,5}$ familiarity and uptake of them is not quantified. These guidelines recommend both intranasal corticosteroids (INCS) and saline irrigation/nasal douching (ND), for which there are strong recommendations for use, based on recent Cochrane reviews ${ }^{6-8}$. Hospital Episode Statistics (HES) Data shows that approximately 40,000 sinus operations are performed (mostly for CRS), in England and Wales each year, which is the progression of management when medical treatment in isolation has failed ${ }^{9}$. A recent ENT-UK commissioning guideline underpins the need for adequate medical management and compliance with ND and INCS use for at least 3 months before referral to secondary care and possible surgical intervention $^{10}$. In a recent Canadian study it was demonstrated that only $20 \%$ of adult patients who received a diagnosis of CRS within the previous 3 years and had not undergone sinus surgery, had utilised their INCS indicating approximately $80 \%$ had failed to use a single unit of INCS and thus identifying a gap in the quality of care ${ }^{11}$. Currently there are an estimated 120,000 secondary care outpatient encounters for CRS per year in England and Wales ${ }^{12}$ and this could represent an unnecessary burden if primary medical treatment is not being best utilised; extrapolating the above Canadian data that $80 \%$ of patients failed to achieve this would translate to a cost of over $f 15$ million in secondary care referrals.

This article is protected by copyright. All rights reserved. 
The aim of this specific analysis of the data from the Chronic Rhinosinusitis Epidemiology Study (CRES) was to quantify the use of medications specific to CRS and for other comorbidities at a point of contact with secondary care and thus determine the degree of compliance with optimal medical management of CRS prior to that contact.

\section{Methods}

\section{Study design and setting}

The CRES was approved by the Oxford C Research Ethics Committee (Ref: 07/H0606/100), sponsored by the University of East Anglia (UEA) and funded by the Anthony Long and Bernice Bibby Trusts. Details of the full methods used for the whole study can be seen in the overview publication ${ }^{13}$. In summary, the CRES aimed to identify differences in socioeconomic variables and quality of life between patients with chronic rhinosinusitis and healthy controls and was conducted as a prospective case-control multi-centre study across the UK involving 30 sites between 2007 and 2013; adoption of the study on to the NIHR portfolio in 2012 saw recruitment of over 600 participants in 1 year. Any patients presenting to secondary care ENT outpatient clinics and diagnosed with CRS (as defined by the criteria laid out in the European Position Paper on Rhinosinusitis and Nasal Polyps ${ }^{1}$ (see above) by an Otorhinolaryngologist), were invited to complete the study questionnaire regardless of symptom or disease severity or duration, and regardless of any prior interventions. Control subjects were also recruited but do not form part of this specific analysis.

\section{Variables and data sources}

The study specific questionnaire (appendix 1) was anonymous and therefore no consent was taken but implied through participation, as approved by the ethics committee. Participant information leaflets were provided. Patients were classified by sub group of CRS (CRSsNPs, CRSWNPs or allergic fungal rhinosinusitis (AFRS) by an Otorhinolaryngologist prior to completion of the questionnaire. Questionnaires were either completed before leaving the clinic or taken home and returned by post in Freepost envelopes. The returned questionnaires were then scanned into a database electronically but the electronic records were then checked by two members of the research team for accurate correlation with the paper questionnaire and for missing data. The return rate for questionnaires during the NIHR portfolio phase of the study was $66 \%$.

The study questionnaire included the question "Do you have any regular medications? Yes/No" followed by a free text box asking participants to list any current medication use.

This article is protected by copyright. All rights reserved. 
The qualitative arm of the CRES was undertaken in 2012. This consisted of qualitative interviews with 21 patients with CRS were purposively selected to explore their experiences of CRS and its management. These patients were all recruited via the Rhinology clinic at James Paget University Hospital, Great Yarmouth. A thematic analysis of the transcripts was undertaken and the results from this study are published in full separately ${ }^{14,15}$ but results relevant to this analysis are considered here.

\section{Participants}

Patients were recruited at the first point of contact during outpatient consultation in secondary care, regardless of prior management in either primary or secondary care and regardless of prior surgical intervention. They were classified by sub group of CRS (CRSsNPs, CRSWNPs or AFRS) by a clinician on the basis of their history and endoscopic and/or CT findings, prior to completion of the questionnaire. Controls who had no diagnosis of nasal or sinus conditions were recruited from amongst family and friends of those attending ENT outpatient clinics (regardless of cause) and from amongst hospital staff, provided they met the criteria below.

\section{Inclusion criteria:}

Criteria for diagnosis of chronic rhinosinusitis (CRS) with or without polyps (EPOS guidelines) ${ }^{1}$ :

Symptoms must be present for at least 12 weeks and include:

- nasal blockage/obstruction/congestion and/or nasal discharge (anterior/posterior nasal drip)

- and either facial pain/pressure and/or reduction or loss of sense of smell and additionally:

- endoscopic signs of: polyps and/or mucopurulent discharge primarily from middle meatus and/or; oedema/mucosal obstruction primarily in middle meatus

- and/or CT changes: mucosal changes within the ostiomeatal complex and/or sinuses

Patients classified as AFRS adhered to either the Bent and Kuhn criteria (see above) or the modified Vancouver criteria ${ }^{16}$.

\section{Exclusion criteria:}

- Patients unable to comprehend written English.

- Patients under the age of 18 years.

This article is protected by copyright. All rights reserved. 
Sample size calculation and statistical analysis

The sample size calculation was based on the primary outcome of the study, which was to look for common associations between socioeconomic factors and CRS. This is detailed in the overview publication of the study ${ }^{13}$. For the purposes of these analyses we have used descriptive statistics; differences in the rates of medication use between groups were assessed by Chi-Squared tests.

\section{Results}

A total of 1,470 participants' questionnaires were available for analysis; 1249 with CRS and 221 controls. The age range was $18-102$ years (mean 52 ) with $54 \%$ who were male; further details of the demographics of the study participants is available in the study overview publication $^{13}$.

Participant flow

As detailed in figure 1, six participants had incomplete information in the medication section of the questionnaire, leaving 1243 participants. A total of 899 had answered positively to taking medications with a respective 850 having recorded details of medications taken. As the AFRS group was small, we have merged it with the CRSwNPs group and analysed only the two main CRS phenotypic groups and the controls.

Missing data

Subjects identified in figure 1 with missing data were excluded from the analysis in keeping with the primary aim of this analysis. Table 1 shows further details of the excluded cases based on the text box entries.

Baseline currently used therapy for CRS

Only $1 \%$ of CRS participants reported current use of ND and only $15 \%$ of all CRS participants reported current use of INCS with a significantly higher uptake in the CRSwNPs group (18.4\%) than the CRSsNPs group (11.8\%) $(p=0.002)$; see table 2. Oral corticosteroid and antibiotic use at the time of participants completing the questionnaire was low (1-3\%). There is no evidence of a difference in social deprivation (as denoted by the index of multiple deprivation (IMD) between those prescribed CRS medication and those not ( $p$ > 0.05 for all comparisons; table 2). Patients were also grouped into regional clusters to look for geographical variation. Using the following clusters there were no significant signs of variation in uptake ( $p>0.05$ ): South of England and London, East Anglia, Midlands, North of England, Wales, Scotland (table 3).

This article is protected by copyright. All rights reserved. 
Asthma-related medications

Table 4 shows the use of asthma-related inhalers that are found to be significantly higher in the CRSwNPs group than the CRSsNPs group (16\% and $20 \%$ in CRSWNPs versus $8 \%$ and $9 \%$ in CRSsNPs for non-steroidal and steroidal inhalers respectively; $(p<0.001)$. This is however much lower than the reported rates of asthma in the two groups ( $21 \%$ and $51 \%$ ).

Non-CRS medications

Analysis of the remaining therapeutic groups noted some key differences between the two phenotypic groups as charted in table 5 . ACE-inhibitors and $\alpha$-blockers were significantly more prevalent in CRSWNPs $(p=0.04,0.03)$ and $\beta$-blockers, NSAIDs and opiate analgesics significantly more prevalent in CRSsNPs $(p<0.01)$.

CRS and Mood disturbances

The rates of depression and anxiety in CRS from the CRES have been reported elsewhere ${ }^{17}$, however it is pertinent to note that the reported rates of depression are much higher $(20 \%$ in CRSwNPs and 25\% in CRSsNPs) than the use of antidepressants themselves (table 6); $7 \%$ in CRSWNPs and $13 \%$ in CRSsNPs.

Qualitative study

The qualitative sub-study found that patients reported issues with prescribed treatment in primary care ${ }^{15}$. Most participants described several courses of different, often ineffective treatments, which were not always reviewed. It was clear that referral to secondary care based on a lack of symptomatic response to 3 months of topical treatment did not always occur for our participants due to both patient and clinician preferences.

'On and off I've used nasal sprays, it was a sort of a bit hit and miss really I might think 'oh it's a bit bad I'll go to the chemist and get something".

"I've now obviously got to do (a nasal spray) (after being seen in secondary care) but I've only ever had that once... a lot of the time. I would have antibiotics and that would clear it very briefly'

Most described several courses of different, often ineffective treatments, which were not always reviewed.

'Everything I tried was so random.'

I was put onto Betnesol nasal drops, remained on them until last year [without significant benefit. Patient had been on this treatment for 40 years].

There were negative views and misconceptions about topical medications.

'The nasal sprays they make it a lot worse... it irritates my eyes and stuff to the point where I'm sneezing 100 times and you know it just comes out and I can't keep it in'

This article is protected by copyright. All rights reserved. 
'If that cost $£ 10,000$ for an operation that's $£ 2,000$ for drugs they go cheap route.'

\section{Discussion}

Key results

The low prevalence of current use of CRS medication may reflect poor prescribing (including advice on how to best use topical treatments), poor adherence to the prescription or poor recall. It may also reflect the fact that sprays and rinses are more burdensome to use than taking tablets, as described in our qualitative interviews or that they are not seen as 'proper' medications since they are sprays not tablets ${ }^{15,17}$. Furthermore, it may simply be that patients have tried medical therapy but failed to derive significant benefit or did not tolerate them, so have stopped taking them.

Strengths and Limitations

The study is a large cross-sectional study including a varied population from across the United Kingdom. It is the largest research study of CRS in UK to date. In contrast to other epidemiological studies in CRS, patients recruited were diagnosed by an otorhinolaryngologist according to international guidelines. The study design had some limitations, it was a self-reported study which predisposes to recall bias. It is possible that some patients may not have considered intranasal medications when asked about medication use, however they have reported inhalers so we expect that the impact of this on the study findings is small. They may have also not considered ND as a regular medication, however both our qualitative work and anecdotal evidence from GP meetings suggests that advice regarding ND in primary care is scarce and steam inhalation is more often recommended to patients. From qualitative interviews we know that some found ND uncomfortable or difficult to integrate into the daily routine, but others are able to tolerate it and in fact may find it helpful ${ }^{18}$. The fact that the CRES data reflects medication use at one moment in time along the patient's journey, is also a limitation.

Interpretation

Looking at the wider picture, one international study demonstrated that one in three CRS patients in primary care have poorly controlled symptoms ${ }^{19}$; the feedback from our participants in the qualitative sub-study also highlighted poor symptom control as a problem. The rhinosinusitis commissioning guidelines produced by ENT UK in conjunction with the Royal College of Surgeons of England recommend that CRS patients have received ND and INCS for 3 months before referral to secondary care ${ }^{10}$ and this is derived from the European position paper of which there is a summary version for GPs ${ }^{20}$. However this low use of primary medical treatment is not unique to the UK as shown by a recent Canadian study showing the same rate of INCS uptake (20\%) and with large geographical variations ${ }^{11}$. Another study of 60 patients following endoscopic sinus surgery found that overall, $57.4 \%$ of

This article is protected by copyright. All rights reserved. 
patients were non-adherent to their prescribed nasal medication regime ${ }^{21}$. Whilst there are certainly parallels with our findings in CRES we did not appreciate any regional variations in the use of CRS-related medications.

With regards to non-CRS medications, use of steroid and non-steroid inhalers was higher amongst those with CRSwNPs compared to those with CRSsNPs. This was likely to be due to their higher prevalence of asthma. Use of $\beta$-blockers and NSAIDs were lower in this group, which was also likely to be due to a higher prevalence of asthma (contra-indicated). Use of $\alpha$-blockers was higher amongst CRSwNPs and since it is mostly used for prostatic hypertrophy, the difference may be due to a male preponderance in this group. The difference in antidepressant use may reflect the fact that facial pain is more common in CRSsNPs and correlates with findings that mood and emotional wellbeing are poorer in this subgroup, as discussed with the qualitative results and in a separate analysis from CRES of mood disturbance in CRS $^{15,17}$.

\section{Generalisability}

Inevitably these patients were referred to secondary care due to failure of primary care treatment and doesn't reflect those who were not referred. Primary care patients who have not been referred may all be managing well on INCS and therefore not needing a referral whereas those where treatment doesn't work may be unlikely to continue with treatment. However, the population studied in CRES represents those who are typically managed within ENT clinics countrywide.

Adherence to medical regimens is an important issue, particularly in the management of chronic conditions. These findings are consistent with a World Health Organization report, which stated that, on average, $50 \%$ of patients are not adherent to long-term therapy for chronic illnesses. They stated that poor adherence is the primary reason for suboptimal clinical benefit in chronic diseases, causing medical and psychosocial complications of the disease, reducing quality of life, and wasting health care resources ${ }^{22}$. Careful patient education may help improve this situation, including reassurance regarding the safety of long-term treatment with newer formulations of intranasal steroids that have very low systemic bioavailability. Improved communication from ENT specialists to primary care regarding proposed treatment duration is also important.

\section{Conclusion}

The reported use of baseline medical therapy in CRS appears to be very low. This is likely to represent a combination of poor patient compliance, possible perceived lack of effectiveness and a lack of familiarity with current guidelines amongst both general practitioners and some specialists despite national, European and International guidelines for the medical management of CRS in both primary and secondary care. Work is needed to understand any barriers to implementing guidelines including disseminating them to all practitioners involved in the care of CRS patients and to encourage good compliance with

This article is protected by copyright. All rights reserved. 
treatment including sound advice on usage of topical medications. Improvement of medical management may serve to reduce unnecessary burden on existing healthcare resources for this common condition by ensuring timely referral and definitive management when needed.

\section{Key points}

- Long term topical therapy is the cornerstone to managing chronic rhinosinusitis.

- Current levels of compliance with nasal douching and intranasal corticosteroids are likely to be poor.

- Clinicians in both primary and secondary care need to work together to encourage good compliance and ensure where possible guidelines are adhered to for best use of healthcare resources.

\section{References}

$1 \quad$ Fokkens W.J., Lund V.J., Mullol J. et al. (2012) European Position Paper on Rhinosinusitis and Nasal Polyps 2012. Rhinol Suppl, 3 p preceding table of contents, 1-298

2 Hastan D., Fokkens W.J., Bachert C. et al. (2011) Chronic rhinosinusitis in Europe - an underestimated disease. A GA2LEN study. Allergy. 66, 1216-1223

3 Hopkins C., Holy C.E. \& Philpott C.M. (2015) Care Pathway of Patients With Chronic Rhinosnusitis In The UK. In British Academic Conference in Otorhinolaryngology, Liverpool

$4 \quad$ Gulliford M.C., Dregan A., Moore M.V. et al. (2014) Continued high rates of antibiotic prescribing to adults with respiratory tract infection: survey of 568 UK general practices. BMJ Open. 4, e006245

$5 \quad$ Orlandi R.R., Kingdom T.T., Hwang P.H. et al. (2016) International Consensus Statement on Allergy and Rhinology: Rhinosinusitis. Int Forum Allergy Rhinol. 6 Suppl 1, S22-209

6 Chong L.Y., Head K., Hopkins C., Philpott C., Burton M.J. \& Schilder A.G. (2016) Different types of intranasal steroids for chronic rhinosinusitis. Cochrane Database Syst Rev. 4, CD011993

$7 \quad$ Chong L.Y., Head K., Hopkins C. et al. (2016) Saline irrigation for chronic rhinosinusitis. Cochrane Database Syst Rev. 4, CD011995

8 Chong L.Y., Head K., Hopkins C., Philpott C., Schilder A.G. \& Burton M.J. (2016) Intranasal steroids versus placebo or no intervention for chronic rhinosinusitis. Cochrane Database Syst Rev. 4, CD011996

9

(2013) Hospital Episode Statistics. Department of Health

This article is protected by copyright. All rights reserved. 
10 Hopkins C., Philpott C., Carrie S. et al. (2016) Commissioning Guide: Rhinosinusitis. . ENT UK/Royal College of Surgeons of England, London

11 Rudmik L., Xu Y., Liu M., Bird C., Kukec E. \& Quan H. (2016) Utilization Patterns of Topical Intranasal Steroid Therapy for Chronic Rhinosinusitis: A Canadian Population-Based Analysis. JAMA Otolaryngol Head Neck Surg. 142, 1056-1062

12 NHS (2015) Health Episode Statistics

13 Philpott C., Erskine S., Hopkins C. et al. (2016) A case-control study of medical, psychological and socio-economic factors influencing the severity of chronic rhinosinusitis. Rhinology. 54, 134-140

14 Erskine S.E., Notley C., Wilson A.M. \& Philpott C.M. (2015) Managing chronic rhinosinusitis and respiratory disease: a qualitative study of triggers and interactions. J Asthma. 52, 600-605

15 Erskine S.E., Verkerk M.M., Notley C., Williamson I.G. \& Philpott C.M. (2016) Chronic rhinosinusitis: patient experiences of primary and secondary care - a qualitative study. Clin Otolaryngol. 41, 8-14

16 Philpott C.M., Javer A.R. \& Clark A. (2011) Allergic fungal rhinosinusitis - a new staging system. Rhinology. 49, 318-323

17 Erskine S.E., Hopkins C., Clark A. et al. (2017) Chronic rhinosinusitis and mood disturbance. Rhinology

18 Keerl R., Weber R., Muller C. \& Schick B. (1997) [Effectiveness and tolerance of nasal irrigation following paranasal sinus surgery]. Laryngorhinootologie. 76, 137-141

19 Lange B., Holst R., Thilsing T., Baelum J. \& Kjeldsen A. (2013) Quality of life and associated factors in persons with chronic rhinosinusitis in the general population: a prospective questionnaire and clinical cross-sectional study. Clin Otolaryngol. 38, 474-480

20 Thomas M., Yawn B.P., Price D. et al. (2008) EPOS Primary Care Guidelines: European Position Paper on the Primary Care Diagnosis and Management of Rhinosinusitis and Nasal Polyps 2007 - a summary. Prim Care Respir J. 17, 79-89

21 Nabi S., Rotenberg B.W., Vukin I., Payton K. \& Bureau Y. (2012) Nasal spray adherence after sinus surgery: problems and predictors. J Otolaryngol Head Neck Surg. 41 Suppl 1, S49-55

22 Organization; W.H. (2003) Adherence to long-term therapies-evidence for action. , Switzerland (ed)

\section{Acknowledgements}

Thank you to Ms Jane Woods for her dedicated work in recruitment to the study and cleaning of the CRES data. Thank you to Mr Jim Boardman for writing a lay summary of the main CRES for patients to read.

This article is protected by copyright. All rights reserved. 


\author{
Author contributions according to ICMJE statement \\ Carl Philpott - Chief investigator, study design and wrote the first draft of the paper \\ Sally Erskine - Contributed to subsequent drafts and analysis of the results; conducted qualitative \\ sub-study \\ Rupert Smith - Contributed to subsequent drafts and analysis of the results \\ Allan Clark - Study design, statistics and final draft \\ Remaining authors - Contribution to manuscript, local principal investigator
}

\title{
Declaration of interests
}

All authors have completed the Conflict of Interest Statement.

\section{Transparency declaration}

The lead author affirms that the manuscript is an honest, accurate, and transparent account of the study being reported; no important aspects of the study have been omitted and any discrepancies from the study as planned (and, if relevant, registered) have been explained. The researchers were independent of the funders in their conduct of the study.

\section{Patient involvement statement}

Patients were involved in a pilot of the original questionnaire in 2006 and a public and patient involvement panel was involved in revisions to the questionnaire and protocol in 2011. Patients were made aware of the study recruiting through links with the patient charity Fifth Sense (www.fifthsense.org.uk) and a lay summary of the main findings of the overall CRES have been disseminated to members of the charity.

\section{Data sharing statement}

Patient level data and full dataset with technical appendix will be available from the corresponding author at C.Philpott@uea.ac.uk. Patient consent was not obtained for the main CRES but was for the qualitative sub-study, but the presented data are anonymised and risk of identification is low and the potential benefits of sharing these data outweigh the potential harms because they help to inform and improve future practice for the benefit of global patient care.

This article is protected by copyright. All rights reserved. 
Table 1: Medications reported by subgroup

\begin{tabular}{|c|c|c|}
\hline Medication & CRSwNPs (n=651) & CRSsNPs $(n=553)$ \\
\hline ACE Inhibitor & $45(6.91 \%)$ & $23(4.16 \%)$ \\
\hline Alpha Blocker (Inc. Doxazosin) & $31(4.76 \%)$ & $13(2.35 \%)$ \\
\hline Analgesic (Unspecified) & $3(0.46 \%)$ & $1(0.18 \%)$ \\
\hline Antibiotic & $10(1.54 \%)$ & $16(2.89 \%)$ \\
\hline Anticonvulsant & $13(2.00 \%)$ & $16(2.89 \%)$ \\
\hline Antidepressant & $46(7.07 \%)$ & $75(13.56 \%)$ \\
\hline Antihistamines & $64(9.83 \%)$ & $46(8.32 \%)$ \\
\hline $\begin{array}{l}\text { Antihypertensive } \\
\text { (Other - Including Bendrofluazide) }\end{array}$ & $66(10.14 \%)$ & $47(8.50 \%)$ \\
\hline Antihypertensive (Unspecified) & $18(2.76 \%)$ & $13(2.35 \%)$ \\
\hline Antiplatelet/Anticoagulant (Inc. Aspirin) & $48(7.37 \%)$ & $41(7.41 \%)$ \\
\hline Beta Blocker & $17(2.61 \%)$ & $32(5.79 \%)$ \\
\hline Diuretic (Exc. Bendrofluazide) & $7(1.08 \%)$ & $5(0.90 \%)$ \\
\hline $\begin{array}{l}\text { DMARD/Biologic Agent } \\
\text { (Inc. Methotrexate) }\end{array}$ & $6(0.92 \%)$ & $4(0.72 \%)$ \\
\hline Excluded $^{\star \star}$ & $23(3.53 \%)$ & $21(3.80 \%)$ \\
\hline Hormone Replacement Therapy & $6(0.92 \%)$ & $12(2.17 \%)$ \\
\hline Inhaler (Unspecified) & $42(6.45 \%)$ & $13(2.35 \%)$ \\
\hline Laxative & $2(0.31 \%)$ & $2(0.36 \%)$ \\
\hline Nasal Spray (Unspecified) & $8(1.23 \%)$ & $14(2.53 \%)$ \\
\hline Non-Opiate Analgesic & $11(1.69 \%)$ & $18(3.25 \%)$ \\
\hline Non-Steroid Inhaler & $105(16.13 \%)$ & $42(7.59 \%)$ \\
\hline Non-Steroid Nasal Spray & $4(0.61 \%)$ & $4(0.72 \%)$ \\
\hline NSAID (Exc. Aspirin) & $11(1.69 \%)$ & $27(4.88 \%)$ \\
\hline Opiate Analgesic & $20(3.07 \%)$ & $35(6.33 \%)$ \\
\hline Other* & $156(23.96 \%)$ & $102(18.44 \%)$ \\
\hline
\end{tabular}

This article is protected by copyright. All rights reserved. 


\begin{tabular}{|l|l|l|}
\hline Proton Pump Inhibitor & $63(9.68 \%)$ & $60(10.85 \%)$ \\
\hline Sinus Rinse & $9(1.38 \%)$ & $5(0.90 \%)$ \\
\hline Statin & $88(13.52 \%)$ & $65(11.75 \%)$ \\
\hline Steroid (Oral) & $12(1.84 \%)$ & $16(2.89 \%)$ \\
\hline Steroid Inhaler & $141(21.66 \%)$ & $51(9.22 \%)$ \\
\hline Steroid Nasal Spray & $120(18.43 \%)$ & $65(11.75 \%)$ \\
\hline Thyroid Hormone & $24(3.69 \%)$ & $28(5.06 \%)$ \\
\hline Vitamin/Mineral Replacement & $28(4.30 \%)$ & $23(4.16 \%)$ \\
\hline
\end{tabular}

* Other included any medication which did not fit into any particular group. Examples include eye drops, skin creams.

**Reasons for exclusion included: Unknown medication, condition stated rather than medication, insufficient information.

This article is protected by copyright. All rights reserved. 
Table 2: CRS-related medication use

\begin{tabular}{|l|c|c|c|}
\hline Medication & CRSwNPs (n=651) & CRSsNPs (n=553) & p \\
\hline INCS & $122(18.74 \%)$ & $67(12.12 \%)$ & $\mathbf{0 . 0 0 2}$ \\
\hline Antihistamines & $64(9.83 \%)$ & $46(8.32 \%)$ & 0.363 \\
\hline Nasal Spray (Unspecified) & $23(3.53 \%)$ & $14(2.53 \%)$ & 0.317 \\
\hline Steroid (Oral) & $12(1.84 \%)$ & $16(2.89 \%)$ & 0.2360 \\
\hline Antibiotic & $10(1.54 \%)$ & $16(2.89 \%)$ & 0.107 \\
\hline Sinus Rinse & $11(1.69 \%)$ & $5(0.9 \%)$ & 0.234 \\
\hline
\end{tabular}

Table 3: Effect of index of multiple deprivation (IMD) on use of CRS-related medications

\begin{tabular}{|l|l|l|l|}
\hline Medication & Median IMD no use & Median IMD use & p-value \\
\hline INCS & & & \\
\hline Antihistamines & $15.23(10.23-19.72)$ & $14.89(9.95-18.83)$ & 0.762 \\
\hline $\begin{array}{l}\text { Nasal Spray } \\
\text { (Unspecified) }\end{array}$ & $14.99(10.16-19.45)$ & $16.14(11.30-22.45)$ & 0.376 \\
\hline Steroid (Oral) & $14.94(10.17-10.45)$ & $16.86(11.67-22.10)$ & 0.226 \\
\hline Antibiotic & $14.94(10.16-19.64)$ & $16.78(13.28-21.32)$ & 0.353 \\
\hline Sinus Rinse & $14.99(10.17-19.72)$ & $16.70(11.83-17.45)$ & 0.736 \\
\hline
\end{tabular}

Table 4: Asthma-related medication use

\begin{tabular}{|l|c|c|c|}
\hline Medication & CRSwNPs (n=651) & CRSsNPs (n=553) & p-value \\
\hline Steroid Inhaler & $132(20.28 \%)$ & $48(8.68 \%)$ & $<0.0001$ \\
\hline $\begin{array}{l}\text { Non-Steroid } \\
\text { Inhaler }\end{array}$ & $105(16.13 \%)$ & $42(7.59 \%)$ & $<0.0001$ \\
\hline $\begin{array}{l}\text { Inhaler } \\
\text { (Unspecified) }\end{array}$ & $42(6.45 \%)$ & $13(2.35 \%)$ & 0.0007 \\
\hline
\end{tabular}

This article is protected by copyright. All rights reserved. 
Table 5: Other medications with noticeable subgroup variations

\begin{tabular}{|c|c|c|c|}
\hline Medication & CRSwNPs (n=651) & CRSsNPs (n=553) & p-value \\
\hline ACE Inhibitor & $45(6.91 \%)$ & 234.16 & 0.040 \\
\hline $\begin{array}{c}\text { Alpha Blocker } \\
\text { (Inc. Doxazosin) }\end{array}$ & 314.76 & 132.35 & 0.026 \\
\hline Opiate Analgesic & 203.07 & 356.33 & 0.007 \\
\hline Beta Blocker & 172.61 & 325.79 & 0.005 \\
\hline NSAID (Exc. Aspirin) & 111.69 & 274.88 & 0.002 \\
\hline
\end{tabular}

Table 6: Comparative reports of depression and antidepressant use

\begin{tabular}{|l|c|c|}
\hline & $\begin{array}{l}\text { Consultation with GP for } \\
\text { depression (\%) }\end{array}$ & Antidepressant use (\%) \\
\hline Controls & 15.3 & 6.3 \\
\hline CRSsNP & 24.6 & 13.6 \\
\hline CRSwNP & 20.0 & 7.1 \\
\hline
\end{tabular}

For more detailed results see Erskine et al ${ }^{17}$.

This article is protected by copyright. All rights reserved. 
Figure 1 Legend: Participant flow chart

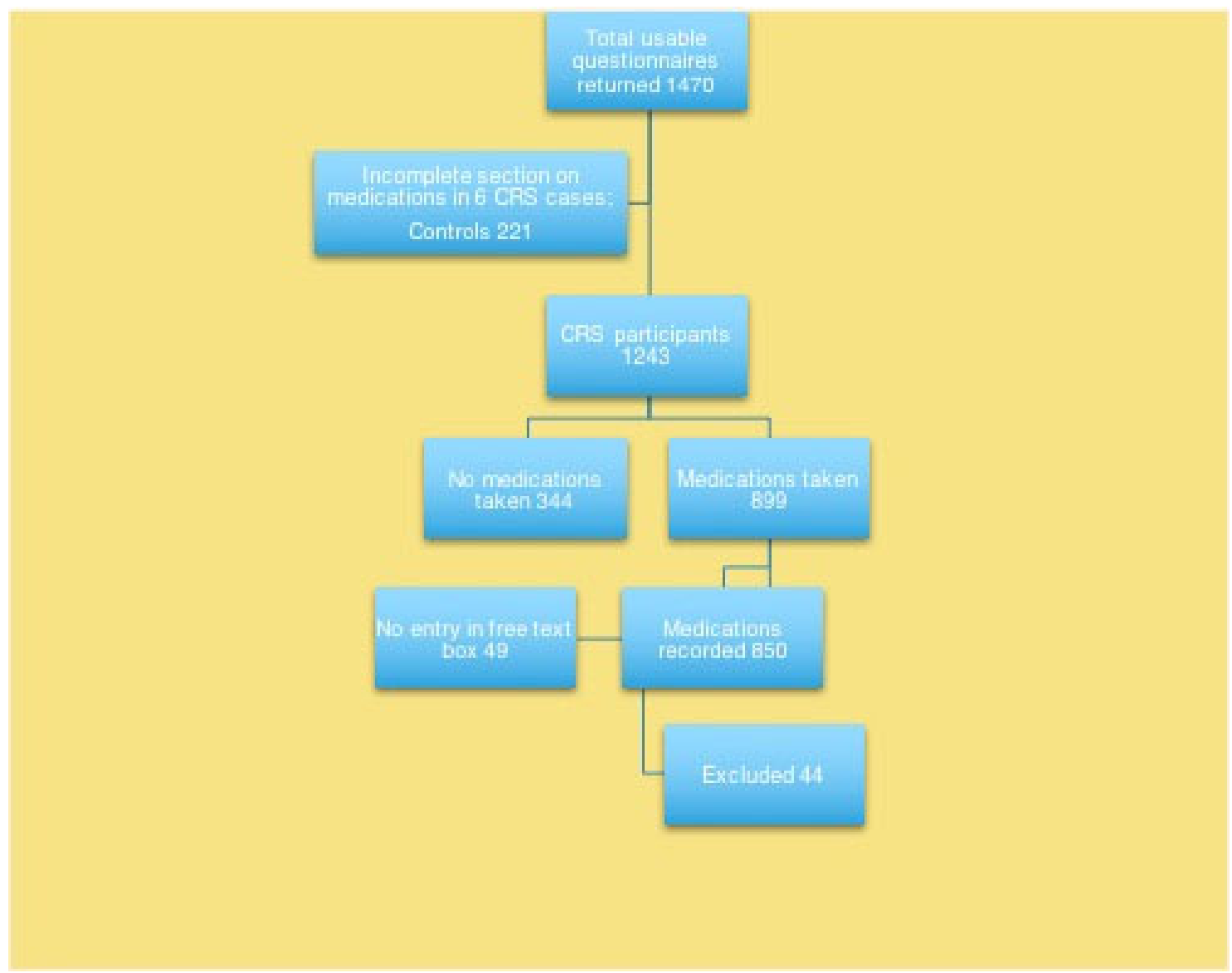

This article is protected by copyright. All rights reserved. 
Please try to fill in ALL parts of the questionnaire, even if you do not have sinus problems and do not feel they are directly relevant to you.

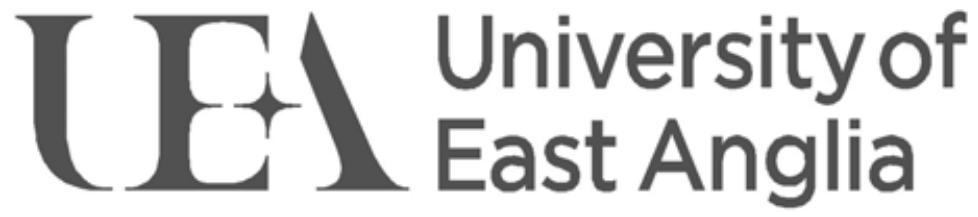

\section{CHRONIC RHINOSINUSITIS EPIDEMIOLOGY STUDY (CRES)}

\begin{tabular}{llll|}
\hline FOR DOCTOR TO COMPLETE: & & & \\
CRS WITHOUT POLYPS & $\square$ & CONFIRMATION OF DIAGNOSIS WITH: \\
CRS WITH POLYPS & $\square$ & CT SCAN $\square$ & ENDOSCOPY \\
CONFIRMEDISUSPECTED AFRS & $\square$ & \\
CONTROL & $\square$ & & \\
\hline
\end{tabular}

\begin{tabular}{|c|c|c|c|c|}
\hline \multicolumn{5}{|c|}{ RECRUITMENT SITE } \\
\hline JPUH $\square$ & NNUH $\square$ & WWL $\square$ & SPIRE $\square$ & $\mathrm{NGH}$ \\
\hline $\mathrm{LDH}$ & $\mathrm{RSCH} \square$ & GUYS $\square$ & QMC $\square$ & $\mathrm{FH}$ \\
\hline $\mathrm{Cl}$ & SRI & $\mathrm{SGH}$ & $\mathrm{BCUH} \square$ & RAH \\
\hline IRH & HEFT & QEH $\square$ & STH & WI \\
\hline OUH & SAMBU $\square$ & СTHB $\square$ & $\mathrm{WHH} \square$ & PHNT \\
\hline $\mathrm{RCH} \square$ & $\mathrm{RGH}$ & AUHNT $\square$ & RBNFT $\square$ & HWPH \\
\hline $\mathrm{DBH} \square$ & Other $\square$ & Other, please specify: & & \\
\hline
\end{tabular}

Please return the questionnaire to the Norwich Medical School, UEA, Norwich - for the attention of Mr Carl Philpott

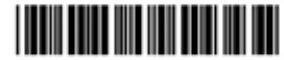




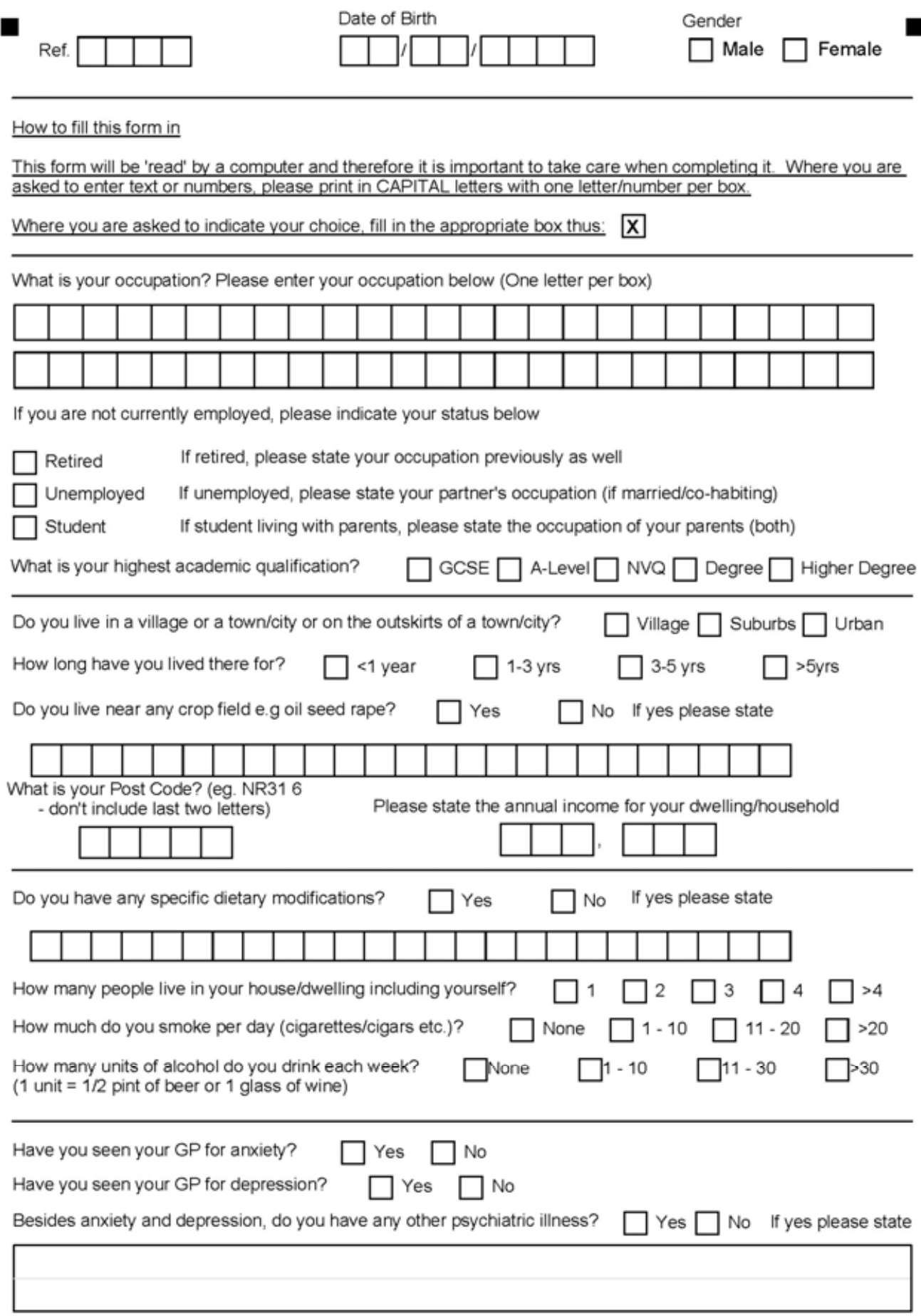

Page 2 of 8

This article is protected by copyright. All rights reserved. 
Ref

How often do you get a cold or sore throat in the space of one year?

$\square$ Never $\square$ Seldom $\square$ Often $\square$ Frequently

Have you had any previous surgery? Yes $\square$ No $\square$ If yes, please specify what and when

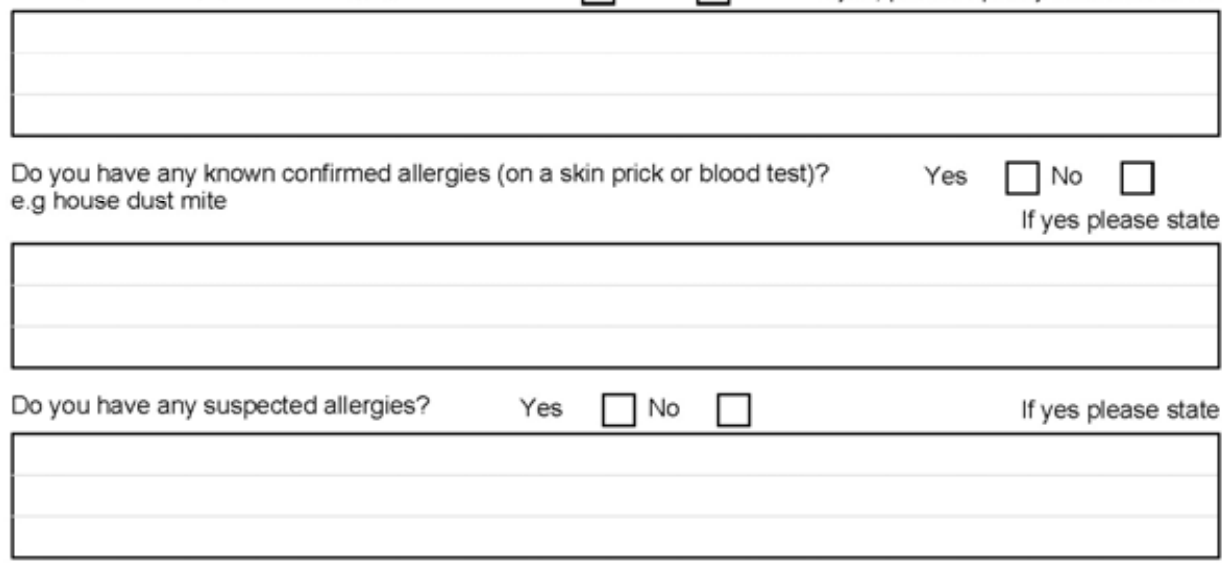

Have you ever experienced any allergy symptoms such as wheezing, runny nose or itchy skin when taking any of the following?

Yes No

Aspirin

Spicy food

Wine

Drinks eg, tea/coffee/fruit juices \& cordials

Nuts

Fruits including tomatoes

Vegetables

$\square \square$

Do you have any of the following?

Asthma?

Chronic obstructive airways disease (emphysema or chronic bronchitis)?

Bronchiectasis (disorder where the air passages widen and produce a lot of mucus)?

Diabetes (loss of blood sugar control)?

Immunodeficience (poor immune response to infections as diagnosed with blood tests)?

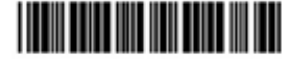

This article is protected by copyright. All rights reserved. 
Ref

Do you have any of the following?

Yes No

Ciliary dysmotility (e.g Cystic Fibrosis, Kartangener's syndrome, Primary Ciliary Dyskinesia)

(disorder where the little hairs on the cells lining the air passages don't work properly)?

Hypothyroidism (underactive thyroid gland)?

Autoimmune disorder (e.g.systemic lupus erythmatosis, rheumatoid arthritis)?

Do you have any other medical conditions?

Yes

If yes please state

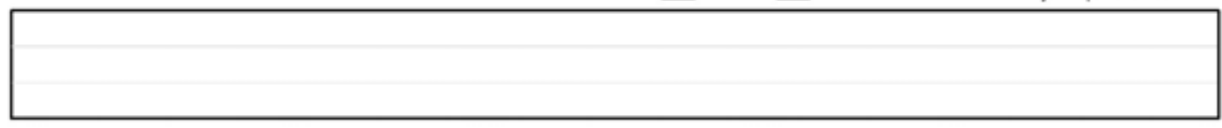

Do you have any regular medications?

Yes

No

If yes please state

Finally, please indicate your Ethnic Group

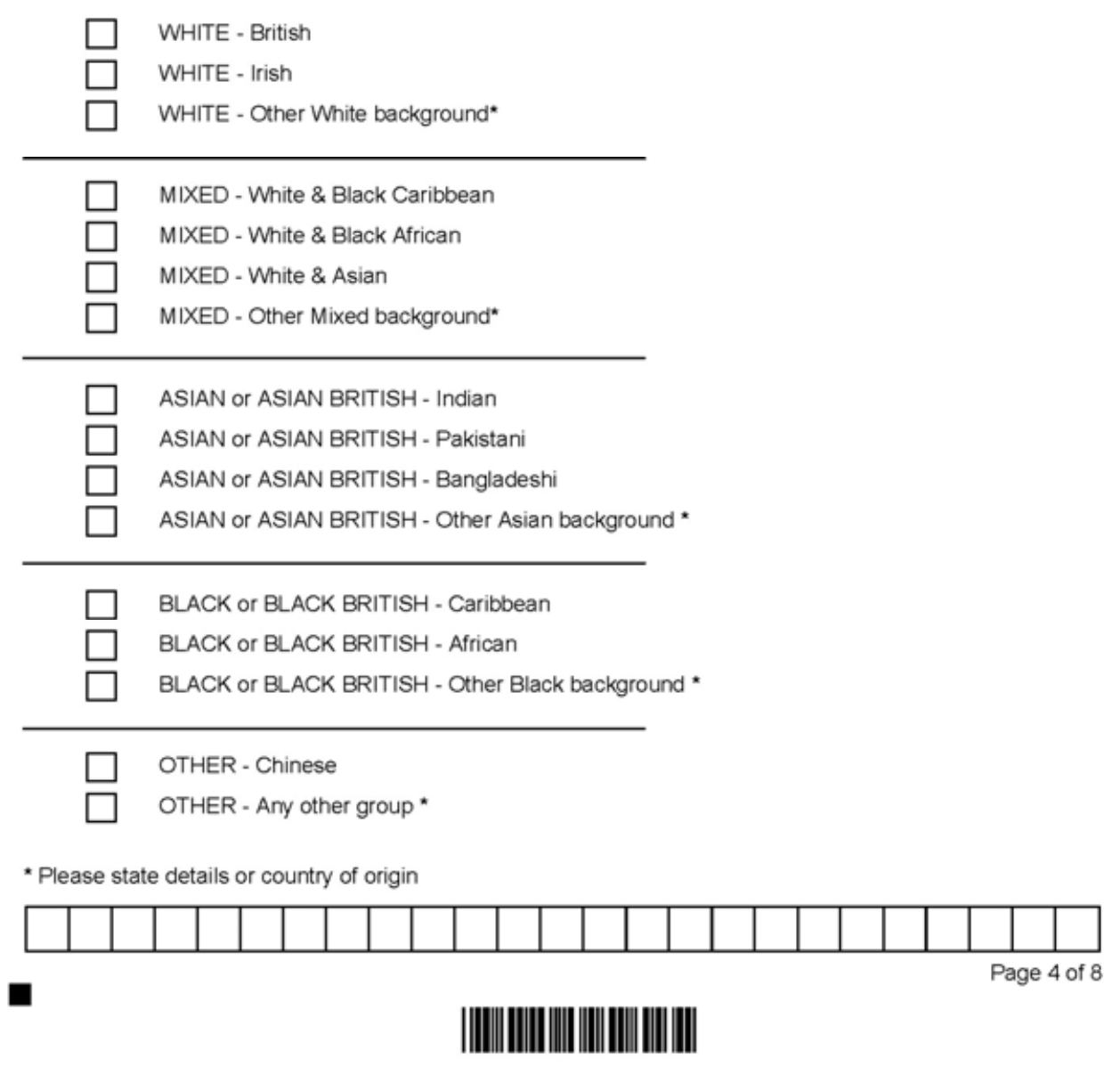

This article is protected by copyright. All rights reserved. 
Ref

\section{SF36 Health Survey}

\section{INSTRUCTIONS:}

This set of questions ask for your views about your health. This information will help keep track of how you feel and how well you are able to do your usual activities.

Answer every question and mark your response by filling in the box thus: $X$

If you are unsure how to answer a question, please give the best answer you can.

1. In general, would you say your health is: (Fill one box only)
Excellent
Very Good
$\square$ Good
$\square$ Fair
Poor

2. Compared to one year ago, how would you rate your health in general now? (Fill one box only)

Much better than one year ago?

Somewhat worse now than one year ago?

Somewhat better than one year ago?

Much worse than one year ago?

About the same as one year ago?

3. The following questions are about activities you might do in a typical day. Does your health now limit you in these activities? If so, how much? (Fill one box only per activity)

$\begin{array}{ccc}\begin{array}{c}\text { Yes, } \\ \text { Limited }\end{array} & \begin{array}{c}\text { Yes, } \\ \text { L Limited }\end{array} & \begin{array}{c}\text { Not } \\ \text { Limited }\end{array} \\ \text { A Little } & \text { At All }\end{array}$

Vigorous activities, such as running, lifting heavy objects, participating in strenuous sports

Moderate activities, such as moving a table, pushing a vacuum cleaner, bowling or playing golf.

Lifting or carrying groceries

Climbing several flights of stairs

Climbing one flight of stairs

Bending, kneeling or stooping

Walking more than a mile

Walking several blocks

Walking one block

Bathing or dressing yourself 
Ref

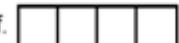

4. During the past 4 weeks, have you had any of the following problems with your work or other regular activities as a result of your physical health? (Fill one box only per problem)

Cut down on the amout of time you spent on work or other activities
Accomplished less that you would like
Were limited in the kind of work or other activities
Had difficulty performing the work or other activities
(for example, it took extra effort)

5. During the past 4 weeks, have you had any of the following problems with your work or other regular activities as a result of any emotional problems (e.g. feeling depressed or anxious? (Fill one box only per problem)

Yes No

Cut down on the amout of time you spent on work or other activities

Accomplished less that you would like

Didn't do work or other activities as carefully as usual

6. During the past 4 weeks, to what extent has your physical health or emotional problems interfered with your normal social activities with family, friends, neighbours or groups? (Fill one box only)
Not at all
Slightly
Moderately
Quite a bit
Extremely

7. How much physical pain have you had during the past 4 weeks. (Fill one box only)

$\begin{array}{llll}\text { None } & \square & \text { Moderate } & \square \\ \text { Very Mild } & \square & \text { Severe } & \square \\ \text { Mild } & \square & \text { Very Severe } & \square\end{array}$

8. During the past 4 weeks, how much did pain interfere with your normal work (including both work outside the home and housework)? (Fill one box only)
Not at all
Slightly
Moderately
Quite a bit
Extremely

Page 6 of 8

This article is protected by copyright. All rights reserved. 
Ref

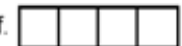

9. These questions are about how you feel and how things have been with you during the past 4 weeks. Please give the one answer that is closest to the way you have been feeling for each item? (Fill one box only per item)

$\begin{array}{cccccc}\begin{array}{c}\text { All of } \\ \text { the }\end{array} & \begin{array}{c}\text { Most of } \\ \text { the }\end{array} & \begin{array}{c}\text { A good } \\ \text { bit of }\end{array} & \begin{array}{l}\text { Some } \\ \text { of the }\end{array} & \begin{array}{l}\text { A little } \\ \text { of the }\end{array} & \begin{array}{l}\text { None } \\ \text { of the }\end{array} \\ \text { time } & \text { time } & \text { the time } & \text { time } & \text { time } & \text { time }\end{array}$

Did you feel full of life?

Have you been a very nervous person?

Have you felt so down in the dumps that nothing could cheer you up?

Have you felt calm and peaceful?

Did you have a lot of energy?

Have you felt downhearted and blue?

Did you feel worn out?

Have you been a happy person?

Did you feel tired?

$\square$

$\begin{array}{ll}\square & \square \\ \square & \square \\ \square & \square \\ \square & \square \\ \square & \square \\ \square & \square \\ \square & \square \\ \square & \square \\ \square & \square\end{array}$

10. During the past 4 weeks, how much of the time has your physical health or emotional problems interfered with your social activities (like visiting friends, relatives etc) (Fill one box only per item)

$\square \quad$ All of the time
$\square \quad$ Most of the time
$\square \quad$ Some of the time
$\square \quad$ A little of the time
$\square \quad$ None of the time

11. How TRUE or FALSE is each of the following statements for you? (Fill one box only per item)

$\begin{array}{llll} & \begin{array}{c}\text { Definitely Mostly } \text { Don't } \\ \text { True Mostly Definitely }\end{array} \\ \text { I seem to get sick a little easier that other people } & \square & \square\end{array}$

This article is protected by copyright. All rights reserved. 
Ref: \begin{tabular}{l|l|l|l|l}
\hline & & & & \\
\hline
\end{tabular}

\title{
Snot - 22 Questionnaire
}

\author{
INSTRUCTIONS:
}

Below you will find a list of symptoms and social/emotional consequences of your nasal disorder. We would like to know more about these problems and would appreciate your answering the following questions to the best of your ability. There are no right or wrong answers and only you can provide us with this information. Please rate your problems over the last two weeks.

Considering how severe the problem is when you experience it and how frequently it happens, please rate each item below on how "bad" it is by filling in the box that corresponds to how you feel. (Fill one box only per item)

Then, pick the 5 that are the most important items affecting your health and fill in the corresponding box in the grey column on the right.

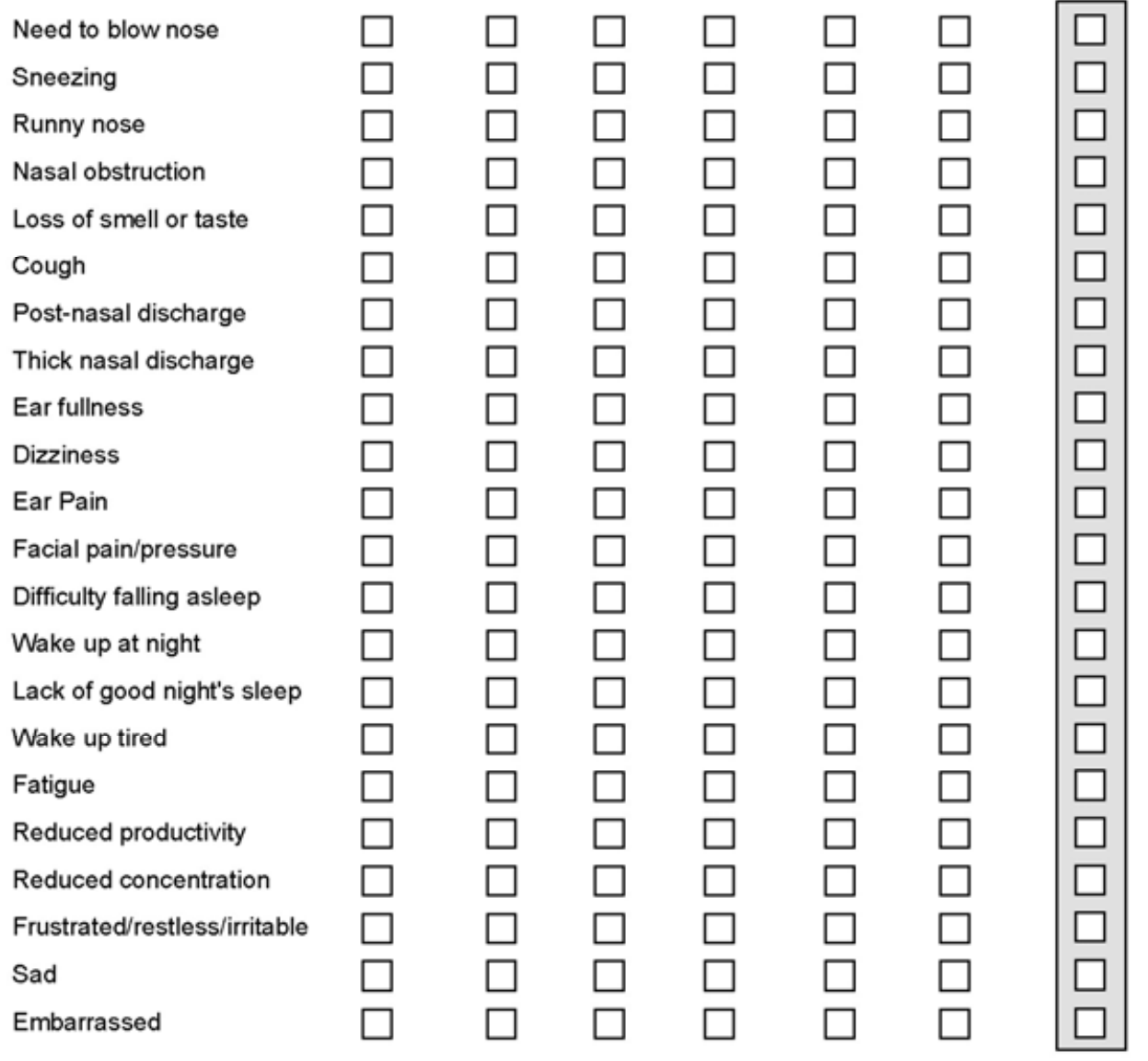

Thank you for taking part in this survey Page 8 of 8

This article is protected by copyright. All rights reserved. 